\title{
АТРИБУТЫ ДЕГУМАНИЗАЦИИ КУЛЬТУРЫ В КОНТЕКСТЕ ДИНАМИКИ «БЕГСТВА ОТ СВОБОДЬ»
}

\section{DEHUMANIZATION OF CULTURE AND ITS ATTRIBUTES THROUGH THE DYNAMICS OF THE "ESCAPE FROM FREEDOM"}

D. Vetrov

Summary: The article aims at redefining the dehumanization of modern Western culture to produce and describe the specific attributes of the phenomenon and various aspects of its functioning through revisiting the nature of humanism, based on the notion of a free subjective reason. An attempt is made to delve into the history of humanism and functioning thereof in various cultural contexts, so as to analyze its relations with anti-humanism (be it described in terms of "closed society" or "escape from freedom") and dehumanization of culture. In the frame of this research are listed and described such attributes of dehumanization as: mechaniscism of life, mythology and myth creation, and intransitive media, which contribute to infiltration of myth.

Keywords: anti-humanism, corporatism, dehumanization, humanism individualism, media, mechanicism, mythology, open society, subject.
Ветров Дмитрий Николаевич

Аспирант, Институт кино и телевидения (ГИТР); преподаватель, Московский государственный лингвистический университет vetrov.interprete@mail.ru

Аннотация: В статье рассматривается возможность выдвинуть последовательное определение дегуманизации культуры и описать атрибуты функционирования дегуманизации, которые проистекают из определения гуманизма, основанного на понимании субъективного разума свободного индивидуума. Автором предпринята попытка рассмотреть исторический контекст понятия гуманизма и условия его функционирования в различных социокультурных контекстах, чтобы описать, каким образом гуманистические основания Западной культуры оказываются вовлечены в диалектические отношения, связанные с их отрицанием: антигуманизмом (описанном в терминах «закрытого общества» или «бегства от свободы»), лежащим в основе дегуманизации культуры и её атрибутов, среди которых в рамках данного исследования, выделены и описаны: механистичность жизни, мифотворчество и медиальность нетранзитивных средств массовой коммуникации, в том числе выступающих как катализатор мифологии.

Ключевые слова: антигуманизм, гуманизм, дегуманизация, индивидуализм, корпоративизм, медиа, механицизм, мифология, открытое общество, субъект.

попытки представить модерное искусство «как сферу, в которой модерн соприкасается с архаическим» [там же, c. 96-97].

Следуя за мыслью Шеллинга, Ницше обращается к романтизму в поисках искусства («поэзии», «музыки»), которое бы, в отличие от спекулятивного разума модерна, стало новой мифологией, обладающей объединяющей силой (утраченной) религии. Лучше сказать, философия должна была, по мысли Шеллинга, уступить место искусству посредством мифа. Того же жаждал Ницше, который сперва воспринял идеи романтиков о новой тотальности, но вынужден был отбросить романтизм, чья трактовка образа Диониса была ему принципиально чужда: в то время как «новая мифология романтиков должна была бы вернуть пропавшую солидарность, но не отказываться от эмансипации ... индивидуализированных перед лицом единого Бога личностей», Ницше постулировал такого Диониса, который «радикально избавляет от проклятия идентичности и тождества, который отменяет принцип индивидами.» [там же, с. 101-102].

Дух декаданса русского «серебряного века», в ходе которого также принимались попытки примирить объективно-исторический и субъект-центрированный разум («...ницшеанский дионисизм своеобразно транс- 
формирован Блоком в концепцию истории» [Паперный, 1979, с. 95]), способствовал восприятию идей Ницше на волне интереса к античности и стремления, помимо прочего, «в случае символистов построить новую русскую культуру как возрождение античности» [там же, с. 90]. Однако принцип дионисийской оргиастической тотальности, внушал, с одной стороны, воодушевление (так, Вяч. Иванов трансформировал антиномию дионисийского и аполлонического в антиномию соборности и индивидуализма, что связано с его «стремлением найти адекватное истолкование драматизму предреволюционной эпохи со свойственным ей широким развитием массового народного движения» [там же, с. 92]), с другой же - отчаяние. Как указывает М.В. Паперный, статья и доклад Блока «Крушение гуманизма» (1919) выражает историческое мироощущение, отмеченное «крайним духовным радикализмом и трагическим самоотречением» [там же, с. 103]: ведь допущение, что «на арене европейской истории появилась новая движущая сила - не личность, а масса, что означает наступление кризиса гуманизма» [Блок, 1962, с. 95] - означает и конец собственной индивидуальной работы Блока-гуманиста, который вынужден принести себя в жертву стихии масс, повинуясь объективной (телеологии) истории.

Здесь нам важно указать на другой, помимо Ницше, источник, реакцией на который, вероятно, стал доклад Блока. Это работа Николая Пунина и Евгения Полетаева «Против цивилизации».

Как указывает А.В. Рыков, «трактат Пунина как и «Крушение гуманизма» Блока 1919 года, посвящен обоснованию дихотомии культура/цивилизация» [Рыков, 2016, с. 179]. Оба произведения сходны и другими чертами: милитаризм Пунина и Полетаева перекликается с идеей эстетики войны у Блока, проистекающей из его понимания духа музыки; роднит их и естественно-биологический принцип возникновения человека нового типа, и расизм [там же, с. 180-181].

В контексте дискурса о гуманизме как движении, в основе которого лежит принцип индивидуализма свободной человеческой личности [Блок, 1962, с. 94], важно подчеркнуть некоторые ключевые положения авторов, касающиеся непосредственно личности и гуманизма: 1) «индивид - лишь носитель энергии, а не ее источник» (источник - общество); 2) «индивидуальное творчество - такой же миф, как индивидуальное сознание; эра лирического индивидуализма миновала»; 3) «существует только народ и благо народа и расы. Отдельные индивиды могут, конечно, пострадать или погибнуть, но это необходимо и гуманно» [Полетаев, Пунин, 1918, с. 37]. Иными словами, в трактате постулируется национальный монизм (холизм, в терминологии Поппера) и примат корпорации над индивидом.
Что также немаловажно, авторы «Против цивилизации» указывают, что моделью для их проекта служит Древняя Греция [там же, с. 2]. Между тем, эвокация (или же радикальная апология) досократовской эпохи Греции в трактате Пунина-Полетаева интересна тем, что апеллирует не к реально существовавшему образованию, но к утопическому конструкту, подробнейшим образом изложенному в «Государстве» Платона. Для нас не столь важно устанавливать, были ли Пунин и Полетаев прямыми эпигонами Платона, однако между двумя текстами есть немало схожего, что позволяет отнести их к манифестам антигуманизма, лежащего в основе дегуманизации культуры на современном этапе.

Прорабатывая текст «Государства», Платон преследовал цель, которую весьма просто сформулировать, и даже достаточно легко обосновать, если иметь представление об историческом контексте политической борьбы, наблюдавшейся в Греции с начала V по середину IV вв. до н.э. Как пишет Карл Поппер, социальная инженерия Платона проистекает из стремления «избежать гераклитовской текучести» и противостоять историческому распаду за счет социальной революции, которая бы привела к установлению такого государственного порядка «который был бы настолько совершенен, что уже не принимал бы участия во всеобщем ходе исторического развития» [Поппер, 1992, с. 56]. Иными словами, «в социальной области теория форм и идей открывает путь для создания определенного вида социальной инженерии, позволяя открыть средства задержки социальных изменений путем построения "наилучшего государства", очень близкого к идее или форме государства, которое не может подвергаться распаду» [Поппер, 1992, с. 63].

Наглядной моделью платоновского идеального государства послужил, очевидно, Лакедемон, целью которого было «остановить всякое изменение и вернуться к племенному строю» [там же, с. 227]. Однако Спарта, как не могла быть для Платона идеальным образованием, не могла служить таковым и в глазах его читателей: к середине четвертого века, когда была написана работа, оно к уже дискредитировало себя «нравственным нигилизмом» и «политикой силы» своих тиранов, которые в оказании своей поддержки лаконофилу Критию, надеявшемуся на фактор поражения Афин в Пелопоннесской войне, проявили жесточайшее насилие и тем самым «оскорбили чувство справедливости у граждан Афин». «Государство» - это не что иное как «эвокация» мифического (а по Платону - идеального) Золотого века, основанного «на убеждении, которое вновь утвердило бы старые ценности племенного строя, противопоставив их вере открытого общества» [там же, с. 242]. (Любопытно, что для последующих поколений утопистов все идеальные государства преследовали цель не остановки прогресса, но химерической идеи всеобщего счастья или блага, которое у Платона является лишь вуалью для ис- 
тинной цели удержания развития).

Идеи Платона очевидно повлияли и на Н.А. Бердяева, который интерпретировал Платона как провозвестника «грядущей ночной эпохи», наступившей после заката эллинизма [Бердяев, 2012, с. 516]. В своем сочинении «Новое Средневековье» (1924) философ транслирует популяризированные Шпенглером предположения о закате цикла Нового времени, или о закате «рационального дня новой истории» [Бердяев, 2012, с. 512], выступая апологетом новой эпохи, в которой «воля к культуре» станет доминировать над «волей к жизни». Бердяев постулирует отказ от «ереси гуманизма» [там же, с. 519-520], оперируя главным образом новозаветными ценностями, в связи с чем выдвигает принцип отказа от свободы (бессмысленности свободы), обосновывая его указанием на онтологическую пустоту устремления к освобождению от внешних по отношению к индивиду целей: «Свобода духа есть неотъемлемое и вечное достижение. Но для чего, во имя чего должно было совершаться освобожде ᄀние? Этого не знает дух Нового времени. Он не имел или не знал своего во имя. Во имя человека, во имя гуманизма, во имя свободы и счастья человеческого. Но тут нет никакого ответа. Нельзя освободить человека во имя свободы человека, не может быть сам человек целью человека. Так упираемся мы в совершенную пустоту» [там же, с. 523].

Здесь Бердяев задает вопрос, более рациональный ответ на который дал спустя почти два десятилетия Фромм, анализируя флуктуацию феноменов, которые он назвал «негативной» и «позитивной» свободой. Негативную свободу Фромм, как и Тойнби, иллюстрирует ветхозаветным мифом о грехопадении, метафорически транслирующем «возникновение напряжения цивилизации» (о котором говорил Поппер), связанным с утратой уз с природой и с обретением свободы от физической зависимости от собственного (непосредственного) окружения: «Социальная история человека началась с момента его перехода из состояния единения с миром к осознанию себя как существа, отдельного от окружающей природы и людей. Однако ... индивид продолжал быть тесно связанным с физическим и общественным миром, из которых вышел. Нарастающий процесс освобождения личности от изначальных уз, ... который мы можем назвать индивидуализацией, достиг, по-видимому, своего пика в современной истории в века между Реформацией и настоящем временем» [Фромм, 2018, с. 34-35]. Эту свободу Фромм называет негативной по её характеру «свободы от», о чем говорит здесь Бердяев. Эта свобода, согласно выводам, самого Фромма, ведет к чувству одиночества, которое в свою очередь приводит к неврозам, лежащим в основе социальных потрясений.

Описывая современное общество как «абстрактное», в противовес конкретным традиционным обществам за- крытого типа, Поппер пишет: «картина абстрактного общества при котором биологическое устройство людей, издревле живших в соответствующих этому устройству органических первобытных обществах, изменилось незначительно, и оставшиеся социальные потребности не могут быть удовлетворены при разрыве непосредственных личных связей, что ведет к анонимности, одиночеству и несчастью фиксирует только одни потери большинство социальных групп современного открытого общества (за исключением некоторых счастливых семейных групп) не создают действительных условий для общественной жизни и не обладают никакой реальной функцией в жизни общества в целом. Однако есть и несомненные приобретения. Личные отношения нового рода могут возникнуть только там, где в них можно вступить свободно, где они не определяются случайностями рождения с ослаблением биологических или физических связей, большую роль начинают играть духовные, и т.п. связи» [Поппер, 1992, с. 219-220].

Однако согласно Фромму, отчаяние от одиночества, непременно вытекающего из негативной «свободы от», ведет к «бегству от свободы», которое лежит в основе дегуманизирующих тенденций, связанных с авторитарными режимами. В свою очередь, авторитарные режимы суть выражение убеждения в том, что «жизнь определяется силами, внешними по отношению к личности, её интересам, её желаниям» [Фромм, 2018, с. 169].

Таким образом, апология средневековья (не важно, «нового» или «старого») представляется таким же проявлением дегуманизирующего корпоративизма, как и эвокация закрытого общества античности у апологетов тоталитаризма. Обращение взгляда на прошлое, согласно Фромму, является одной из черт авторитарной ментальности: «Для авторитарного характера активность коренится в основополагающем чувстве бессилия, которое он стремится преодолеть. В этом смысле активность означает действие во имя чего-то высшего, чем сам индивид. Такое возможно во имя Бога, прошлого, природы, долга, но никогда во имя будущего, нерожденных поколений, тех, кто лишен власти, или самой жизни» [там же, c. 169].

Апологетом средневековья (по крайней мере в тех местах, где это уместно с т.з. критики гуманизма и индивидуализма) выступает современник Бердяева А.Ф. Лосев, чья критика гуманизма связана с утверждением себя индивидом как «некой самостоятельной субстанции ни в чем не имеющей нужды для своего существования, для своего бытия» [Лосев, 2001, с. 259].

Видя в эпохе феодализма отражение социализма своего времени, Лосев постулирует недопущение развития изолированной личности: «Свободное искусство и наука есть всецело достояние либерально-буржуазной культу- 
ры», [буржуазное] искусство только и живет средствами изолированной личности», «поэтому логический вывод из коммунизма - это искоренение также искусства». Таким образом, «феодализм и социализм вполне тождественны в том отношении, что оба они не допускают свободного искусства, но подчиняют его потребностям жизни» [там же, с. 127].

Замечание Лосева ценно тем, что обращение к проблеме функционирования искусства для нас важны для понимания социокультурной динамики: оно помогает так или иначе проследить эволюцию ментальности, когда речь заходит о столь отдаленных от нас эпохах, что других инструментов, помогающих приблизится к объективной оценке доминирующих жизненных установок этих обществ почти не остается.

Утверждая, что человек Ренессанса более не нуждается для своего бытия во внешнем объекте, Лосев указывает, что эта независимость от внешнего мира отражена в особенностях живописи: «[Возрожденское] мироощущение выражено в живописи - основном возрожденческом искусстве: живопись дает мир не как самостоятельную вещь, но как объект восприятия и познания» [там же, с. 259-260]. Здесь (и ранее) Лосев допускает определенную вольность, постулируя архитектуру и скульптуру как исключительные атрибуты античного мира («античный пантеизм всегда или архитектурен, или скульптурен. Живопись, поэзия, музыка для него слишком духовны, слишком бесплотны» [там же, с. 238]), а развитие живописи ассоциируя с Возрождением. Вопервых, из трех излюбленных авторов Вазари, только Рафаэль не был скульптором, однако являлся признанным архитектором, наряду с двумя другими великими именами: Леонардо и Микеланджело. Во-вторых, как указывает П.А. Сорокин, греческая и римская живописная традиция также была связана с выдающимися именами (в первую очередь, Полигнота) [Сорокин, 2006, с. 151], владевшими в том числе искусством перспективы. И если противопоставлять античность Средневековью и Новому времени, то необходимо различать неоднородные этапы собственно античного искусства (которые могут выступать зеркальным отражением либо средневекового, либо ренессансного искусства), согласно флуктуациям идеациональной и чувственной форм искусства: с точки зрения трансцендентного, сверхчувственного характера художественного творчества (нравственного, патриотического, религиозного, и т.д.), можно сказать, согласно Сорокину, что средневековье близко в этом отношении доклассической античности, в то время как Ренессанс, условно считая себя зеркалом классического эллинизма, характерен чувственной визуальностью, доминирование которой продолжается до нашего времени [там же, с. 132-133], и, по всей видимости, является свидетельством нарастающего индивидуализма.
Следуя, таким образом, за рассуждением Бердяева о наступлении нового средневековья, можно попытаться усмотреть в явлениях начала XX века ситуацию, В том или ином смысле напоминающую (новое) средневековье, которая по объективным причинам оказалась крайне неустойчивой, поскольку была основана на ложных эсхатологических убеждениях в грядущем или уже свершившемся закате и упадке. На него, на первый взгляд, словно указывают сразу несколько атрибутов: рассуждая в терминах Тойнби, внутренний пролетариат рабоче-крестьянской массы отделился от меньшинства бывшей элиты и основал собственную универсальную церковь (философию младогегельянства), отличную от религии бывшей власти. Этой эпохе приблизительно соответствует развитие идеационального стиля в искусстве (супрематизма), которое, согласно социокультурной динамике Сорокина, отражало сверхчувственную ментальность доклассической Греции (пришедшей на смену умершей чувственной культуры прежнего критомикенского общества [там же, с. 147-148]); аналогичным образом, идеациональное искусство средневековья пришло на смену перезрелой чувственной александрийской культуре позднего эллинизма; в терминологии Бердяева, идеациональная ментальность соответствует «ночной эпохе»: «выходу за пределы эллинского дня» [Бердяев, 2012, с. 516], аналогично той, что он усматривает в собственной современной ему культуре «нового средневековья». Однако эта модель наталкивается на ряд противоречий.

Если продолжать следовать логике Тойнби, надлома (Западной) цивилизации в результате социалистической революции не произошло (она носила локальный характер и непосредственно не повлияла на структуру Западного общества, если не считать мирного движения рабочих во всех государствах со свободным рынком).

В то же время, если обращаться к симптоматике художественного творчества, искусство авангарда, хотя и было внешне идеациональным, имело совершенно иные предпосылки, нежели «глубоко религиозное, патриотическое, назидательное» [Сорокин, 2006, с. 152] искусство доклассической Греции: напротив, по словам Сорокина, хотя «символизм, конструктивизм, экспрессионизм, ... кубизм ... резко и решительно порвали с визуализмом, они не стали подлинным идеационизмом или хотя бы идеализмом» [там же, с. 180]. Более того, в искусстве начала XX века, как в мировом, так и в советском, прослеживается страсть к гигантомании (в случае последнего наиболее наглядными примерами служат проекты татлинской башни и здания Дворца Советов; ср. с Колоссом и Галикарнасской гробницей Мавзола IV в до н.э.), а также внимание к бытовым темам и деталям, что является неотъемлемым атрибутом чувственно-визуального искусства. 
Отличие современных художников, чьи работы, исходя из принципа отрицания чувственного визуализма, можно по ошибке принять за проявление идеациональной ментальности, состоит в том, что «современный художник - высокопрофессиональный специалист. Он хочет быть свободным от предписаний религии, от моральных приличий - от всего, за исключением своего воображения. Он ни в коем случае не желает быть просто анонимным творцом в коллективе, каковыми были художники-идеационалисты» [там же, с. 185].

Этот факт служит и следствием, и доказательством того, что «новое средневековье» и новый корпоративизм, основанный на отрицании свободного индивида уже принципиально невозможен, а всякая попытка повернуть вспять процесс индивидуализации и освобождения индивида (будь то, в терминах «закрытого общества» Поппера, «задержанного общества» Тойнби или «бегства от свободы» Фромма) - и будет наиболее ярко выраженной дегуманизацией.

Для нас интересно обратить внимание на то, что, согласно Тойнби, античный мир и европейское средневековье не являются фазами единого непрерывного развития (по критериям единства вселенской церкви пролетариата и универсального государства, поэтому говорить о фазе возникновения «напряжения цивилизации» как о моменте рождения нашей цивилизации, по Попперу, может оказаться неправомерным, чем и объясняется новый виток дегуманизирующих тенденций европейского средневековья. Возможно, достижения афинской демократии и сократовского гуманизма остались незыблемым прорывом лишь в рамках античной цивилизации, которая пресеклась в Средние века, когда варварские народы севера Европы только начинали переживать кризис напряжения цивилизации, ранее пережитый Гераклитом и концептуализированный Платоном. Если это замечание верно, то принцип гуманистического индивидуализма не находится в стихийном отношении флуктуации с его противоположностью: иными словами, никакой объективный исторический или трансцендентный порядок не обуславливают угасания индивидуализма и наступления корпоративного закрытого общества в какой-либо момент времени. На этот факт указывает и то обстоятельство, что чувственно-визуальная форма искусства так и не сменилась идеациональной с тех пор, как была утверждена Ренессансом. Таким образом, любые попытки идеологов воспользоваться принципом «негативной свободы», чтобы утвердить неизбежность наступления нового закрытого общества являются искусственными, и основываются исключительно на мифотворчестве, будь то сознательным или неосознаваемым. Так, упомянутые модели эвокаций являются, на наш взгляд (наряду с любым апеллированием к авторитетам прошлого), частью мифологии, которая может служить целям сторонников как закрытого, так и открытого общества.

На этом основании, выделяем такой атрибут дегуманизации как мифотворчество (а также, под дегуманизацией подразумеваем насильственное поддержание веры в миф на этапе его прекращения его функционирования, связанное с понятием репрессивной цивилизации).

\section{Некоторые предварительные выво $\Delta ы$ и определения}

Поскольку понятие гуманизма на современном этапе имеет различные контексты и определения, мы считаем необходимым вывести дополнительное определение гуманизма, и отталкиваясь от него определить дегуманизацию как антигуманистическую тенденцию, лежащую в основе тех или иных феноменов и элементов современной западной культуры.

Гуманизм - это утверждение (мировоззрение), согласно которому человеческая жизнь не может подчиняться и определяться трансцендентными или любыми внешними целями и явлениями, если они противоречат развитию, росту и счастью индивида. В формулировании подобного определения мы руководствуемся различными источниками, которые имеют тождественные общие черты. Это, в первую очередь, гуманизм Сократа, согласно учению которого, «в человеке есть божественная искра, разум, а также любовь к истине, доброте, человечности, любовь к красоте и благу. Именно она придает достоинство человеческой жизни. Именно разум делает субъект человечным и дает ему право претендовать на статус цели самой по себе» [Поппер, 1992, с. 236-237]. Схожие положения, которые можно найти у множества авторов (в частности, у Пико делла Мирандолы в «Учении о достоинстве человека»), встречаем у Сартра: «Для экзистенциалиста человек потому не поддается определению, что первоначально ничего собой не представляет. Человеком он становится лишь впоследствии, причем таким человеком, каким он сделает себя сам. Таким образом, нет никакой природы человека, как нет и бога, который бы ее задумал. Человек просто существует, и он не только такой, каким себя представляет, но такой, каким он хочет стать. И поскольку он представляет себя уже после того, как начинает существовать, и проявляет волю уже после того, как начинает существовать, и после этого порыва к существованию, то он есть лишь то, что сам из себя делает. Таков первый принцип экзистенциализма. Это и называется субъективностью, за которую нас упрекают человек прежде всего существует, человек - существо, которое устремлено к будущему и сознает, что оно проецирует себя в будущее. Человек - это прежде всего проект, который переживается субъективно» [Сартр, 1990, с. 323]. 
Хронологический разброс контекстов творчества трех названных авторов, призван указать на непреходящий принцип гуманизма как индивидуализма, который мы имеем в виду.

Итак, мы выделили в качестве основополагающего атрибута дегуманизации (и всякой антигуманистической тенденции) отрицание индивидуализма или отрицание его необходимости. Сама же дегуманизация является практическим выражением тех инструментов и механизмов, которыми данное отрицание постулируется: собственно, атрибутами дегуманизации, которые проистекают из первого основополагающего момента, в котором отрицается ценность и смысл индивидуализма.

Первым атрибутом дегуманизации мы назовем механистичность жизни.

Особенность дегуманизации на современном этапе состоит в том, что она носит имплицитный характер. Как указывает Фромм, «современная демократия [создает убедительную иллюзию того, что она] обеспечила истинный индивидуализм», в том понимании, что «[м]ы гордимся тем, что мы не подчиняемся никакой внешней власти, что мы свободны выражать наши мысли и чувства...» [Фромм, 2018, с. 231-232]. Если, говоря об исторических тоталитарных проектах, берущих начало от Платона, мы упоминали в качестве атрибута дегуманизации примат корпорации над индивидом, то в условиях отсутствия таких «закрытых обществ» механистичность постулирует примат над личностью индустриального способа производства. Разумеется, когда Фромм говорит, что «сегодня человек страдает от того факта, что он превратился в винтик в большой машине, в автомат, от того, что его жизнь стала пустой и утратила смысл» [там же, с. 265], мы воспринимаем это утверждение не в том гротескном смысле, в каком его визуализировал Фриц Ланг в картине «Метрополис», или Чаплин в фильме «Новые времена». Дело не столько в образе промышленного объекта, к которому приставлен человек, но в том, что «принцип работы ради накопления капитала... заставляет человека трудиться ради целей, лежащих вне его, и превращает индивида в слугу той самой машины, которую он создал, и тем самым чувствовать свою личную незначительность и бессилие» [там же, с. 114]. В этой связи, говоря об «орнаменте массы» (и о его иррациональности), Кракауэр указывает, что «рациональная сторона капиталистической экономики - это не просто разум, но разум смутный. Он не включает в себя человека. Функционирование производственного процесса устроено без учета потребностей людей, а сам человек не является основанием общественно-экономического устройства» [Кракауэр, 2014, с. 50].

О принципиальном механицизме, лежащем в основе цивилизации, упоминает и Тойнби, правда выходя за пределы критики индустриального производства, о котором говорят здесь Фромм и Кракауэр: смысл высказывания историка снова заключается в опасности доминирования механицизма над жизнью. Говоря об опасной «механичности мимесиса», как инструмента передачи созидающего волевого импульса, Тойнби пишет о вырабатывании в результате роста цивилизации механических навыков у субъекта: «Восхитившись [изобретательностью Homo Faber], задумаемся над смыслом таких словосочетаний, как "машинное производство", "механическое движение", "механическое поведение", "партийная машина". Здесь явно просматривается не идея триумфа жизни над материей, но, напротив, господства материи над жизнью... продукт творческого ума, обладающий безграничной властью над материальной Вселенной, фактически оборачивается своей противоположностью, становясь инструментом нашего собственного порабощения» [Тойнби, 1991, с. 303-304].

В этом же контексте (опасного) мимесиса мы можем выделить такой атрибут дегуманизации как мифологию и мифотворчество. В главе о «надломе цивилизации» Тойнби указывает, что «мир, где творческая личность живет и трудится, - это общество обычных, простых людей. Задача творческой личности в том и заключается, чтобы эту массу заурядных людей превратить в своих последователей, активизировать человечество, направить его к цели, находящейся вне его самого» [Тойнби, 1991, с. 302]. Таким образом, мы имеем группу «пассивного большинства» и «творческого меньшинства»; последние в том числе являются мифотворцами. Причем этот путь предполагает возможную катастрофу, в случае если мифотворец допускает ошибку [там же, с. 303]. В ряду исторически первых из таких лидеров-мифотворцев, как мы указали вначале, был Платон. Но поскольку рост индивидуализма сопротивляется прямым попыткам отрицать самоценность личности, на современном этапе мифология (в бартовском понимании неподлинности мира, данного нам в культурном опыте, контаминированном вторичными смыслами) прибегает к «похищенному языку». Так, Джон Грей в работе «Соломенные псы» оперирует своими профессиональными знаниями в области философии и истории идей, чтобы постулировать гуманизм как ничтожный миф, наряду с христианством, апеллируя в том числе к работе Роберта Ардри о «территориальном императиве», акцентируя ту часть исследования, где человек рассматривается как обычное животное среди прочих видов [Gray, 2002, p. 4-5].

Катализатором мифотворчества (и любого мимесиса) на современном этапе является медиальность, как дополнительный атрибут дегуманизации, транслирующий мифологии посредством СМК. Как указывает Бодрийяр, особенность медиа в том, что они принципиально нетранзитивны (то есть, понятие «коммуникации», заложенное в названии СМК - это также симулякр, мифо- 
логема сама по себе), ибо не допускают диалога творческого меньшинства с нетворческим большинством: «вся современная архитектура медиа основывается на следующем определении: они суть то, что запрещает ответ» [Бодрийяр, 2007, с. 238]. Таким образом, культура не предлагает иных условий для передачи искры творчества пассивному большинству, кроме как интенсификации миметической механичности, в рамках которой аудитория должна механически следовать целям, находящимся вне каждого отдельного её участника.

Предложенная нами схема атрибутов дегуманизации отталкивается от первичного принципа анти-индивидуализма, но остается открытой для включения в неё новых элементов, в зависимости от особенностей области исследования.

ЛИТЕРАТУРА

1. Бердяев, Николай. Новое средневековье // Бердяев Н.А. Философия неравенства / Составитель и отв. ред. О.А. Платонов. — М.: Институт русской цивилизации, 2012. - 624 с.

2. Блок, Александр. Записные книжки: 1901-1920. / Под общ. ред. В.Н. Орлова, А.А. Суркова, К.И. Чуковского. - М.: Художественная литература, 1965. - 664 с. - С.454-455.

3. Блок, Александр. Крушение гуманизма // Блок, Александр. Собрание сочинений в 8 томах. Т.6. под общей ред. В.Н. Орлова, А.А. Суркова и К.И. Чуковского. - М.: Художественная литература, 1962. - 558 с. - С.94-95.

4. Бодрийяр, Жан. К критике политической экономии знака / пер. с фр. Д. Кралечкин. - М.: Академический проект, 2007. - 335 с. - С.238.

5. Кракауэр, Зигфрид. Орнамент массы: сб. эссе. - М.: Ад Маргинем Пресс, 2014. - 92 с.

6. Лосев А.Ф. Диалектика мифа. / Сост., подг. текста, общ. ред. А.А. Тахо-Годи, В.П. Троицкого. - М.: Мысль, 2001. - 558 с.

7. Ортега-и-Гассет, Хосе. Восстание масс / Хосе Ортега-и-Гассет; пер. с исп. А. Гелескула. - М.: АСТ, 2017. - 256 с. - С.33

8. Ортега-и-Гассет, Хосе. Эстетика. Философия культуры / Вступ. ст. Г. М. Фридлендера; Сост. В.Е. Багно. — М.: Искусство, 1991. — 588 с.

9. Паперный М.В. Блок и Ницше // Ученые записки Тартуского государственного университета. - 1979. - №491. - XXXI. - C.84-106.

10. Полетаев, Евгений. Пунин, Николай. Против цивилизации / Евгений Полетаев, Николай Пунин; с предисл. А.В. Луначарского. - Петербург: 4-я Гос. тип., 1918. -138 c

11. Поппер, Карл Раймунд. Открытое общество и его враги. Т. 1: Чары Платона / Пер. с англ. под ред. В.Н. Садовского. — М.: Феникс, Международный фонд «Культурная инициатива», 1992. - 448 с.

12. Рыков А.В. Политика модернизма. Николай Пунин и Александр Блок. Труды исторического факультета Санкт-Петербургского Университета - 2016. - №25 - C.177-184.

13. Сартр Ж.-П. Экзистенциализм - это гуманизм // Сумерки богов / Сост. и общ. ред. А.А. Яковлева: Перевод. — М.: Политиздат, 1990. — 398 с. — С.323.

14. Сорокин П.А. Социальная и культурная динамика / Питирим Александрович Сорокин; пер. с англ., вст. статья и комментарии В.В. Сапова. - М.: Астрель, 2006. $-1176 c$

15. Тойнби А.Дж. Постижение истории: Пер. с англ. / Сост. Огурцов А.П.; Вступ. ст. Уколовой В.И.; Закл. ст. Рашковского Е.Б. - М.: Прогресс, 1991. - 736 с.

16. Фромм, Эрих. Бегство от свободы / Эрих Фромм; пер. с англ. А.В. Александровой. - М.: АСТ, 2018. - 288 с.

17. Хабермас Ю. Философский дискурс о модерне. Двенадцать лекций / Юрген Хабермас; Пер. с нем. - 2-е изд., испр. - М.: Весь Мир, 2008. - 416 с.

18. Gray, John. Straw dogs: thoughts on humans and other animals. London, Granta Books, 2002. Pp.4-5.

(c) Ветров Дмитрий Николаевич (vetrov.interprete@mail.ru).

Журнал «Современная наука: актуальные проблемы теории и практики» 